\title{
Post-Recession Decision-Making Associated with Adding NCAA Division I Sports Programs
}

\author{
Sloane Milstein ${ }^{1}$ and Zack Damon ${ }^{2}$ \\ ${ }^{1}$ Colorado Mesa University, ${ }^{2}$ University of Central Arkansas
}

\begin{abstract}
Recent college sport headlines highlight the decision to cut teams during the COVID-19 pandemic. Yet, a number of institutions are charging forward and have announced the addition of a team(s) to their athletic offerings. Plymouth State will add men's swimming, Indiana Tech is adding women's ice hockey, and Augustana College just added men and women's water polo. Such additions are somewhat surprising given the difficult economic climate currently facing higher education and intercollegiate athletics.
\end{abstract}

This study sought to identify a structure that NCAA Division I decision-makers took part in when adding a team in previous years. Accordingly, the authors conducted expert-based, in-depth, semi-structured interviews with 15 Division I athletic administrators representing 23 sport teams. The following decision-making phases were identified: Identification, Justification, Evaluation, Acceptance (or Interruptions), and Authorization. Theoretical and practical implications for institutions seeking to grow their sport offerings are provided.

Keywords: intercollegiate athletics, decision-making, athletic administration, NCAA, Title IX

Researchers have examined the impact of removing college football programs at National Collegiate Athletic Association (NCAA) Division I institutions (Hutchinson \& Berg, 2015; Jones, 2014). Primarily associated with the theory of escalation of commitment, the decision-making process for the removal or addition of NCAA Division I sports have been well established (Hutchinson \& Berg, 2015; Jones, 2014). Specifically, in 1981, when the NCAA began tracking intercollegiate athletic participation numbers for men and women, the numbers illustrate the escalation of commitment to grow athletic programs. According to Irick (2019), the number of championship sport teams within NCAA institutions increased to a new high of 19,886 for the 2018-19 academic year; broken down by gender this equates to 10,660 women's teams and 9,226 men's teams.

Despite this growth, which illustrates universities' strong escalation of commitment to athletics (Hutchinson \& Berg, 2015; Jones, 2014), there is a paucity of 
research examining the decision-making process related to the addition or removal of a sport on campus. Leaders across universities and in the athletic departments risk falling into entrapment during decision-making; the process to overcommit or escalate to a decision to justify the initial decision and resources, even if the decision becomes ineffective (Brockner et al., 1986). The literature suggests a number of factors may contribute to the decision-making process, including leadership, expectations of post-recession economics, and potential university-wide impact (Burton \& Welty Peachey, 2014; Mahony \& DeSchriver, 2008).

The decision-making process is a particular aspect in need of further examination within the escalation (or de-escalation, when commitments are reversed or stopped) of commitment phenomenon of adding a sport. This is especially salient given the current state of college athletics and the economic downturn of the United States during COVID-19. A lack of research linking the decision-making process that athletic departments engaged in to the adding or removing of a sport team is surprising, given the important role that finances and revenue play in adding and removing a collegiate sport (Hutchinson \& Bouchet, 2014a). Current leaders and decision-makers of college athletic departments can be better served in their decisions to add or remove a sport during the COVID-19 economic downturn by examining what decision-making processes worked well, and what processes did not work well in the past, during a similar economic downturn.

The need to understand various factors in the decision-making process is further emphasized given the costly nature of engaging in the escalation of commitment (Staw, 1981). Researchers found that despite the media attention on programs removed post-recession, more programs, specifically football, were added in the years immediately after the 2008 recession (Armstrong, 2009; Axson, 2014). Further, the effects of adding a football program have led to an increase in student applications, while also leading to a decline in student quality and retention over time (van Holm \& Zook, 2016). Decisions by leaders in athletic departments in early 2020 have already began to take shape as numerous universities have announced additions of sport teams, such as Plymouth State adding men's swimming, Indiana Tech adding women's ice hockey, and Augustana College adding men's and women's water polo. While the escalation of commitment research related to adding a sport program to a college has focused on economic feasibility studies (van Holm \& Zook, 2016), and financial data of athletic departments (Mahony \& DeSchriver, 2008), little research has focused on the inner-workings or factors related to the decision-making processes to add a sport program. Therefore, the purpose of the current study is to examine what the decision-making processes were when college athletic departments engaged in adding a team to their sport offerings. Further, we fit the decision-making processes into a model to help guide future collegiate sport administrators who may engage in deciding to add a sport to their institutions. Given the important and cyclical relationship between leaders, organizational culture, and decision-making (Schein, 2010), we determined it necessary to focus on the leaders of NCAA Division I athletic departments, athletic directors, and related administrators, who were identified to have been directly involved in the decision to add a sport to their respective university programs. 


\section{Theoretical and Contextual Framework and Review of Literature}

Given our interest in examining the decision-making process and applying the process to the current economic downturn stemming from COVID-19, we decided to limit data to schools that engaged in the adding or removing of a team during a similar economic downturn; post-2008 recession (2009-16). During this time period, researchers documented a significant decline in certain college sport spending, including team travel, and university-level discussions on eliminating sports (Hutchinson \& Berg, 2015; Mahony \& DeSchriver, 2008). We looked at teams that had just been added, those institutions which had committed to adding, and a third group of institutions still determining whether or not to add in the coming years.

Historical records for each institution demonstrated that at some point in time, each university has added one or more teams to gain or maintain the NCAA minimum requirements of teams to remain complaint. However, in many institutional cases, years passed, and conditions and circumstances may have changed. Thus, an institution interested in adding a new sport would likely be dealing with a new process, and is considered unstructured because no predetermined and explicit set of ordered responses exist.

In 2010, Getz and Siegfried (2010) postulated that adding a sport might increase university exposure and thus, increase enrollment. Specifically, Getz and Siegfried stated:

. . . as a form of advertising and public relations or as the consumption of entertainment services, intercollegiate athletics may attract students, thus substituting alternative recruitment expenditures. Simply having Division I sports teams seem to matter more than the success of the teams (p. 359).

Allen (1999) further suggested the presence of a "Flutie Factor", which represents the "appearance" itself by the team or by individual athletes in post-season play, can positively benefit an institution through better imaging and branding (Brooker \& Kloastorian, 1981; McCormick \& Tinsley, 1987).

In addition to increasing the pool of students who apply to a university, several studies illustrated having an NCAA Division I program attracts more students with higher SAT scores (McCormick \& Tinsley, 1987; Sand \& Sloane, 2004). Thus, a larger pool of students attracted to a school due to the athletic program enables an institution to enroll fewer students needing financial assistance (Getz \& Siegfried, 2010). The exact effect of adding a sport program to the quality of a student that a university then attracts remains unclear. van Holm and Zook (2016) found the quality of students added to a university actually declines over time when football is added, potentially due to a relationship between more applicants from a broader academic background wanting to be part of college football's sense of community. Additionally, studies on financial donors demonstrate evidence that alumni who participated in intercollegiate athletics donated more than alumni who did not (Clotfelter, 2003; Monks, 2003; Wunnava \& Lauze, 2001). 
Additional factors impacting college athletic offerings include addressing the need for reform on the field and in the classroom (Benford, 2007), commercialism and amateurism (Bowen \& Levin, 2003), academic integrity (Batley, 2011), and gender equity (Lawrence, Ott \& Hendricks, 2009). As such, the literature provides a number of factors for an athletic director to consider when adding NCAA sports to their offerings. Despite the various factors illustrated by other researchers, there has yet to be a focus on compiling the various factors into a decision-making model. A better understanding of such decision-making processes is warranted.

\section{The Structure of Unstructured Decision Process}

The Structure of Unstructured Decision Process Framework focuses on identifying a structure to describe the unstructured process of strategic decision making at senior levels of organizations through three phases. Mintzberg, Raisinghani, and Theoret (1976) defined a decision as a specific commitment to action (usually a commitment of resources), and a decision-process as a set of actions and dynamic factors that begin with the identification of stimulus for action, and ends with the specific commitment to action. The term "unstructured" refers to decision processes that have not been previously encountered or views of a different form or process for which no predetermined and explicit set of ordered responses exists. The term "strategic" means important actions taken, resources committed, or precedents set (Mintzberg et al., 1976).

The framework of the unstructured process starts with the identification phase where the problem is recognized, a decision is required, and there is a difference between information about the actual situation and the expected standard. Collectively, these factors signal a need for a decision based around the problem which is subsequently clarified and defined. Next comes the selection phase, where a choice is made by screening and evaluating those factors surrounding the encountered problem, potential interruptions, or stopping points and alternates that could be offered or factors that can blocked. Ultimately, the final phase is authorization. We believe that this framework can be applied to decisions to adding or removing sports, particularly when combined with the escalation and de-escalation of commitment phenomena.

\section{Escalation of Commitment}

Escalation of commitment is best described as the negative aspects associated when decision-makers continue to allocate more resources to a sunk cost or initiative (Bouchet \& Hutchinson, 2010). Escalation of commitment has often been combined with entrapment (Brockner, Shaw, \& Rubin, 1979) for a number of decades. Entrapment is described as the continued commitment to an action displayed by a decision-maker in the face of the action having negative effects, at times putting forth more resources to attempt to turnaround the action into positive results despite a low likelihood of such an outcome (Brockner \& Rubin, 1985). Effectively, escalation of commitment and entrapment involve leaders basing current decisions on the amount of time and money already spent on prior decisions and incorporating the opinions of 
too many stakeholders until the main tenets of the decision at hand become convoluted (Bouchet \& Hutchinson, 2010; Brockner et al., 1986). As a leader feels trapped within their previous decisions, they continue to commit to the decision, particularly when there is public knowledge about the parameters surrounding the decision (Brockner et al., 1979). Specifically, Brockner and colleagues (1979) found that when participants in an investment experiment publicly noted their limit of investment and had to make active decisions to continue the investment, participants were less likely to diverge from their earlier, publicly stated limit. Additionally, Brockner et al. (1986) found that when decision-makers faced negative feedback, their escalation of commitment to a decision was higher than those who faced less negative or positive feedback. Related to the same findings, Brockner and colleagues also noted that decision-makers risk becoming further entrapped in their commitment when their identification with the outcomes is highly evident. For example, an athletic director pushing to add a sport that they have publicly championed for, therefore tying their own identity to the addition of a sport, will cause the athletic director to pursue adding the sport even in the face of negative consequences of the outcome, because their identity has been engrained with the outcome of adding the sport. The athletic director is much less likely to reverse course and suggest that the sport not be added, similar to how Brockner et al. (1986) described the danger of identity and decision-making becoming intertwined. This illustrates that when limits or parameters of decisions are publicly known, leaders and decision-makers are more likely to continue on the initial decision and escalate their commitment due to entrapment from public knowledge about the decision.

Escalation of commitment has centered on the connection of five key determinants in an organization throughout time; social, organizational, project, contextual, and psychological (Ross \& Staw, 1993). The social determinant is centered on one's internal processes to reconcile modeling others' behavior and cultural norms expected of leaders in decision-making situations (Bouchet \& Hutchinson, 2011; Ross \& Staw, 1993). Ultimately, social determinants dictate a person's resistance to admit a mistake in their decision-making for the sake of maintaining credibility (Ross \& Staw, 1986). Bouchet and Hutchinson (2011) illustrated an example of social determinants when an NCAA university removes programs and risks losing credibility with their key stakeholders (i.e., alumni, students, and donors).

Organizational determinant is based on aspects of public support for the organization's decision, economic and technical investments into the decision, and how well aligned the decision is with the organization's existing values (Bouchet \& Hutchinson, 2011; Goodman, Bazerman, \& Conlon, 1980). An example of the organizational determinant within the NCAA is how a university relates the athletic department with the brand and marketing efforts of the university as a whole, rather than separating the athletic department and teams from the rest of campus (Bouchet \& Hutchinson, 2011). Next, the project determinant is focused on the economic impact of a decision (Ross \& Staw, 1993). As it relates to NCAA program decisions at the university level, the project determinant is an important aspect for athletic department personnel to vet, given the uncertainty of long-term financial effects that 
decisions hold (Hutchinson \& Bouchet, 2014b). According to Ross and Staw (1993), the contextual determinant incorporates those forces and aspects related to the organization's decision, which expand beyond the organization's boundaries (i.e., beyond their physical facilities). Bouchet and Hutchinson (2011) noted how the escalation decisions for collegiate athletic departments involve and affect stakeholders beyond the campus and playing fields of the athletic departments, such as external stakeholders within the university's state education board of directors. Lastly, the psychological determinant is centered on how one processes their decisions in such a way that leads to the manipulation of data and facts to align with their desired decision's outcome (Ross \& Staw, 1993). Within the current context, the psychological determinant would involve a university leadership team manipulating a feasibility study to show a positive return on investment for adding a sport program.

The five escalation of commitment determinants provide a foundation for understanding the forces surrounding the decision-making process of adding a sport program in an athletic department. Much of the research on collegiate escalation of commitment centered on adding programs (see: Bouchet \& Hutchinson, 2010; 2011; Roy, Graeff, \& Harmon, 2008), however; Hutchinson and Bouchet (2014a; 2014b) focused on de-escalation of collegiate athletic programs and advanced the understanding of how colleges add or remove sport programs.

De-escalation behaviors involve the ceasing or reversing of escalation commitment decisions, in the hopes of avoiding or minimizing negative effectives of previous escalation initiatives (Hutchinson \& Bouchet, 2014b). Further, Keil and Robey (1999) along with Hutchinson and Bouchet (2014b) noted that a finite outcome of de-escalation can be project termination, if a reversal of escalation commitment cannot be achieved. Therefore, it is important that athletic department leaders weigh all escalation determinants and corresponding outcomes before enacting a decision that may need to be de-escalated or terminate the initiative completely at a later time. Oftentimes, examples of de-escalation have involved removing athletic programs or lowering a university's athletic department level of play (for example from Division I to Division II) (Hutchinson \& Bouchet, 2014a). One of the key and contrary findings from Hutchinson \& Bouchet's (2014a) work was the importance of limiting stakeholder input in the decision-making process to de-escalate. Given the overwhelming financial and credibility-based reasons involved in de-escalating (Bouchet \& Hutchinson, 2011; Hutchinson \& Bouchet, 2014b), through the project determinant, limiting stakeholder input (such as alumni, students, and donors) is an important aspect to ensuring the decision-making process to de-escalate does not overemphasize the contextual determinant.

Despite a foundation of research within the escalation of commitment and the de-escalation of commitment phenomena in collegiate athletics, the current research is lacking an understanding of the phenomena's underlying decision-making processes. Exploring the decision-making processes related to adding or removing an athletic team stands as significantly important, given the potential for wasted valuable resources if a university escalates their commitment to a poor decision. Therefore, to help guide our study, we constructed the following research questions: 
RQ1: What are the decision-making phases considered when adding a team to a university's athletic department?

RQ2: What might the new decision-making model look like when adding a team to a university's athletic department?

\section{Methods}

Similar to a recent study, which examined 15 Division I athletic administrators (representing 23 sport teams) who participated in the sport adoption process (Milstein \& Dixon, 2019), our current study involved Division I athletic administrators who were identified as involved in the sport adoption process at their institutions during the 2009-16 time period. The current study endeavors to better understand decision-making factors that involve hierarchical influences present both internally and externally to the university. As such, we outline our research parameters and participants below.

\section{Identifying Research Parameters}

Based on the argument presented earlier, we concluded that the intercollegiate athletic context post-2008 recession would not only offer insight into the decision-making processes, but also contribute topical implications for current athletic administrators during and after the COVD-19 economic downturn. Accordingly, the range of consideration for the current study is 2009-2016. Historical records of each institution revealed that, during the 2009-16 period, each university in our sample added one or more sports to gain or maintain the NCAA minimums of 14 sports, six male and eight female teams. However, in many institutional cases, years have passed and conditions and circumstances may have changed. Therefore, an institution interested in adding a new sport would likely be dealing with a new process, and is considered unstructured because no predetermined and explicit set of ordered responses exists.

\section{Participants}

A purposive sampling approach was used to identify NCAA Division I Athletic directors who fit the above-mentioned study parameters from the NCAA database, and regional Conference Commissioners and Coaches' Associations, and were contacted via e-mail. Subsequently, 15 individuals were recruited to participate in the study (see Table 1); eight identified as male and seven as female, representing six conferences and schools of various sizes. Job titles included: Athletic Director, Director of Athletics, Director of Administration (In Athletics), Deputy Director of Athletics, Vice President of Athletics, Senior Associate Athletic Director, and Associate Athletic Director. Ten of these individuals served in the institutions' highest level of administration (e.g., Athletic Directors, Director of Athletics, Vice President of Athletics) and five held roles associated with a Senior Athletic Administrator (e.g., Senior Associate athletic directors and Associate athletic directors). 
Table 1

Participants'Job Titles

\begin{tabular}{|c|c|c|c|c|}
\hline $\begin{array}{l}\text { Level of } \\
\text { Administration }\end{array}$ & Title & $\begin{array}{l}\text { Number of } \\
\text { Participants }\end{array}$ & $\begin{array}{c}\text { Dual Role as } \\
\text { Senior Women's } \\
\text { Administrator }\end{array}$ & Gender \\
\hline \multirow{5}{*}{ Highest Level } & Athletic Director & 3 & & Male \\
\hline & Director of Athletics & 3 & & Male \\
\hline & $\begin{array}{l}\text { Director of } \\
\text { Administration } \\
\text { (In Athletics) }\end{array}$ & 1 & & Male \\
\hline & $\begin{array}{l}\text { Deputy Director } \\
\text { of Athletics }\end{array}$ & 1 & 1 & Female \\
\hline & $\begin{array}{l}\text { Vice President } \\
\text { of Athletics }\end{array}$ & 1 & & Male \\
\hline \multirow{3}{*}{ Senior Level } & $\begin{array}{l}\text { Senior Associate } \\
\text { Athletic Director }\end{array}$ & 3 & 3 & Female \\
\hline & \multirow{2}{*}{$\begin{array}{l}\text { Associate Athletic } \\
\text { Director }\end{array}$} & 1 & & Male \\
\hline & & 2 & 1 & Female \\
\hline Total & & 15 & 5 & \\
\hline
\end{tabular}

\section{Procedures}

Using a semi-structured interview protocol (Siritarungsri, Grant, \& Francis, 2013), participants were interviewed and audio recorded by phone. The protocol was constructed based on the aforementioned literature related to decision-making processes (Mintzberg et al., 1976). Supplemental questions were used to ensure depth to each answer was received, as is often the case for semi-structured interviews (Siritarungsri et al.,2013). This interview method is well-suited for exploring the decision-making process and enabled us to probe for more information and the clarification of answers. Specifically, Siritarungsri, Grant, and Francis (2013) noted the use of "elite" personnel, or context experts such that the interviewee "can open up little-known aspects of governance, policy and professional culture, and add quality and credibility to qualitative research" (Siritarungsri et al., 2013, p. 75). The protocol began by building rapport with the participant and then moved on to more interpretive and exploratory questions (Siritarungsri et al., 2013). Following each interview, the audio transcription was uploaded to a transcribing service, and then reviewed for accuracy. Transcribed interviews were imported into the ATLAST.ti program to assist in the organization of data and facilitate the identification of themes by coding.

Data were collected until interviews were complete or no new information was uncovered and redundancy had been reached within the process, the procedures, and the scope of the study. A matrix was designed to determine the optimal number of 21 participants for this study, dividing them by sport category, sport gender and size of institution (see Table 2). The actual number of participants in this study was 15 because in the Emerging Sport category (Women's Equestrian) and the Mixed Sport 
category (Rifle Shooting, Fencing, and Skiing) no institutions fit the parameters of this study. Within the categories of men's and women's individual sports at a small school, so few programs were added that the researchers became concerned about ensuring true anonymity.

Table 2

Interview Matrix for Actual Participants

\begin{tabular}{|c|c|c|c|c|}
\hline Category of Sport & $\begin{array}{l}\text { Small School } \\
1,000-2,999 \\
\text { students }\end{array}$ & $\begin{array}{l}\text { Medium School } \\
3,000-9,999 \\
\text { students }\end{array}$ & $\begin{array}{l}\text { Large School } \\
10,000 \text { and more } \\
\text { students }\end{array}$ & $\begin{array}{l}\text { Number of } \\
\text { Teams per } \\
\text { Category }\end{array}$ \\
\hline $\begin{array}{l}\text { Men's Individual } \\
\text { Championship Sport }\end{array}$ & $\begin{array}{l}\text { No School Fits } \\
\text { These Parameters }\end{array}$ & $\begin{array}{l}\text { Track } \\
\text { Golf }\end{array}$ & Golf & 3 \\
\hline $\begin{array}{l}\text { Women's Individual } \\
\text { Championship Sport }\end{array}$ & $\begin{array}{l}\text { No School Fits } \\
\text { These Parameters }\end{array}$ & $\begin{array}{l}\text { Golf (2) } \\
\text { Tennis } \\
\text { Track }\end{array}$ & $\begin{array}{l}\text { Golf }(2) \\
\text { Tennis }\end{array}$ & 7 \\
\hline $\begin{array}{l}\text { Men's Team } \\
\text { Championship Sport }\end{array}$ & $\begin{array}{l}\text { Football } \\
\text { Lacrosse }\end{array}$ & $\begin{array}{l}\text { Lacrosse } \\
\text { Soccer }\end{array}$ & Baseball & 5 \\
\hline $\begin{array}{l}\text { Women's Team } \\
\text { Championship Sport }\end{array}$ & $\begin{array}{l}\text { Sport TBD } \\
\text { Lacrosse }\end{array}$ & Lacrosse & Soccer & 4 \\
\hline $\begin{array}{l}\text { Women's Individual } \\
\text { Emerging Sport }\end{array}$ & $\begin{array}{l}\text { No School Fits } \\
\text { These Parameters }\end{array}$ & $\begin{array}{l}\text { No School Fits } \\
\text { These Parameters }\end{array}$ & $\begin{array}{l}\text { No School Fits } \\
\text { These Parameters }\end{array}$ & 0 \\
\hline $\begin{array}{l}\text { Women's Team } \\
\text { Emerging Sport }\end{array}$ & Sand Volleyball & Sand Volleyball & $\begin{array}{l}\text { Sand Volleyball } \\
\text { (2) }\end{array}$ & 4 \\
\hline $\begin{array}{l}\text { Mixed } \\
\text { Championship Sport }\end{array}$ & $\begin{array}{l}\text { No School Fits } \\
\text { These Parameters }\end{array}$ & $\begin{array}{l}\text { No School Fits } \\
\text { These Parameters }\end{array}$ & $\begin{array}{l}\text { No School Fits } \\
\text { These Parameters }\end{array}$ & 0 \\
\hline $\begin{array}{l}\text { Total per } \\
\text { Institutional Size }\end{array}$ & 5 & 10 & 8 & 23 \\
\hline
\end{tabular}

While the ideal number of participants was set at 21 , the 15 actual participants, whose institutions are summarized in Table 2 represent all three of the Carnegie Foundation classifications for school sizes. Three schools were classified as small (3) $<2,999$ undergraduate students, four as Medium (4) between 3,000-9,999 undergraduate students and seven as large (7) >10,000 undergraduate students. The Carnegie Classification ${ }^{\mathrm{TM}}$ is a framework for recognizing and describing institutional diversity in U.S. higher education for the past four decades. This framework is widely used in the study of higher education, both as a way to represent and control for institutional differences, and also in the design of research studies to ensure adequate representation of sampled institutions, students, or faculty (carnegiefoundation.org 2013). In addition to school sizes, the institutions represented were from six different regions of the country, thus participating in six different conferences. The following regions were represented in this study: Northeast, Southeast, Mid-Atlantic, Midwest, Southwest, and the West Coast. 


\section{Data Coding and Analysis}

The process of coding the transcripts involved "taking text data gathered during data collection, segmenting the sentences or paragraphs into categories, and labeling those categories with a term" (Creswell, 2009, p.186). We also analyzed transcripts in accordance with Patton's (1990) strategies for data analysis (i.e., the process of identifying, coding, and categorizing the primary patterns in the data individually). The coding process consisted of two cycles. First, in-vivo coding with analytic memoing was used to direct the language of the participants as codes (Saldaña, 2016). This coding allowed us to return to the data to inspect, interrogate, and interpret the results to find patterns and explanations during the second cycle of coding (Richards, 2005). Label coding was initially derived from descriptive factors listed in the interview protocol. Annotations that occurred during the interviews, such as participant expressions or attitudes, were added to the transcripts. Next, we considered the importance of the notations by using analytical memos added to the transcripts (Saldaña, 2016). Once the initial transcript was coded, links were made from one set of data (i.e., one participant's account) to another. Following annotations, we reviewed the transcripts, and ideas or a theme's memos were added that came to light. Lastly, we again included linkages between related themes in participants' accounts. Finally, after coding the last of the participant information, we revisited the earlier coded participant interviews for any added clarity and observation that came to light.

\section{Peer Debriefing and Inter-rater Agreement}

A panel of five individuals consisting of two athletic directors not participating in the study, one enrollment and admission specialist, and two graduate students, participated in both the peer debriefing and inter-rater agreement, so as to reduce potential researcher bias. Each member of the panel reviewed participant transcripts and discussed emergent themes with the first author individually. In addition, three inter-raters were emailed a list of codes with corresponding definitions and three randomly selected transcripts. These individuals independently coded the transcripts by hand and shared their findings with the researchers. Next, these individuals were provided a draft of the findings to determine if they agreed with the interpretations. After all materials were reviewed, it was determined that there was consensus in both transcript coding and emergent theme development.

\section{Findings and Discussion}

\section{Emerging Patterns for Decision-Making}

Overall, findings demonstrated a varied process exhibited among study participants about who originated the idea of adding a sport, along with an associated justification and evaluation. In addition, findings highlighted the inclusion process of a variety of stakeholders demonstrating the need to gain institutional support, and obtain authorization before formal implementation. The combination of the two lines of research (unstructured decision-making and escalation of commitment) led us to answer RQ1 
Table 3

Theoretical Frame and Emerging Approach Summarized

\begin{tabular}{|c|c|c|}
\hline & Theoretical Framework & Emerging Approach \\
\hline Phase 1: & $\begin{array}{l}\text { Identification, stimulus and } \\
\text { clarification of the problem. }\end{array}$ & $\begin{array}{l}\text { Opportunity to add a sport } \\
\text { presents itself through a driving } \\
\text { force. }\end{array}$ \\
\hline Phase 2: & $\begin{array}{l}\text { Development, solutions are } \\
\text { sought out. }\end{array}$ & $\begin{array}{l}\text { Justification for adding the sport } \\
\text { must be presented. }\end{array}$ \\
\hline Phase 3: & $\begin{array}{l}\text { Selection, choice is made by } \\
\text { screening and evaluating. }\end{array}$ & $\begin{array}{l}\text { Evaluation of sport to determine } \\
\text { if it is a good fit at the institu- } \\
\text { tion. }\end{array}$ \\
\hline Interruptions: & $\begin{array}{l}\text { Alternates could be offered } \\
\text { up or the initiative could be } \\
\text { blocked altogether. }\end{array}$ & $\begin{array}{l}\text { Acceptance must be gained by } \\
\text { key stakeholders or sport will } \\
\text { not be added. }\end{array}$ \\
\hline Phase 4: & Authorization & Authorization \\
\hline
\end{tabular}

(what are the decision-making phases considered when adding a team to a university's athletic department?) through the following themes that emerged from the data: (1) Driving forces, (2) Justification, (3) Evaluation, (4) Acceptance, (5) Authorization, and (6) Approach and Leadership. Our findings are presented in Table 3. We present the themes with supporting quotes in the following pages.

\section{Initial Discussion}

Escalation of commitment is easily associated with the sport arms race, such as building bigger and better facilities, bringing on big contract coaches, and the recruitment benefits that result from these facets for both student-athletes and the general student body (Getz \& Siegfried, 2010). The climate of athletics has changed drastically in the last 40 years with an increased call for accountability in academics, recruiting, gender equity, and an expectation of sound fiscal practices from both inside and outside of the institutions. Because of the more complex nature of today's higher education environment, the responsibilities of athletic administrators are increasingly demanding. Decisions made must consider the impact on the students, the departments, the institution, and the external environment.

From the findings of this research the Proposed Decision-making Process to Add a Sport to NCAA Division I Institutions model has emerged demonstrating a number of feedbacks, accountability, or buy in loops exist in regards to adding sports. As the findings for each phase are discussed they are framed through the unstructured process, adapted to college sport, and considered through the lens of escalation of commitment. 


\section{Driving Forces}

Within the decision-making process, there is often a discussion about solving a problem. The addition of a sport involves fulfilling the minimum NCAA membership requirement to comply with gender equity mandates or boosting enrollment. However, at some institutions, athletic directors also discussed that being visionary or future oriented, getting in on the ground floor of a new sport, or connecting with students, alumni or the community, were their driving forces for adding a sport. Examples are presented below from a student driven, administrator, athletic department, and trustee perspective.

[Student Driven] I think the initial interest was driven by the student body. The student government association and the executive committee initiated and advocated for a student referendum to help fund the program. [They] presented an extensive list of students' signatures to the university administration who then put together a formal proposal for adoption by the board of trustees (Interview \#9, Football, Large School).

[Institutional Administrator] A new Chancellor came in and decided, probably five-years ago, that it would be studied (Interview \#5, Football, Large School).

[Athletic Department] The notion stemmed from within athletics. Partially it was a little visionary towards the sport [of lacrosse], it's growing and booming, especially in the Northeast and Middle Atlantic area, and [volleyball] was beginning to make inroads ... so this is an opportunity to sort of, be on the cutting edge, by adding two additional sports that were becoming more popular (Interview \#7, Women's Sand Volleyball and Women's Lacrosse, Small School).

[Trustee] I would say we have to give credit to the Trustees. There was a particular Trustee who actually chaired the Admissions Committee of the Trustees, and felt that it would be strategically a plus for us in our recruiting and so forth. $\mathrm{He}$ brought the idea and actually made a gift of a million and a half dollars to help us [with] the cost of getting started (Interview \#10, Men's and Women's Lacrosse, Medium School).

\section{Discussion on Driving Forces and the Social Determinant Association}

Highlighted as a social determinant was a risk of losing credibility with key stakeholders such as alumni, students, and donors. In a number of cases it was a stakeholding group that proposed the sport adoption initiative as noted above and the community who supported the initiative as suggested below.

[Support for Facility] Now, golf we already have a financial gift for. We have a short game facility that is off campus that our men have; and we already have the gift secured to add a wing for the women's golf. We've got a significant plan. (Women's Individual, Large School). 
[Competition Support] We find more and more companies are beginning to provide sponsorship. They are not going to get involved as our big sponsor, but they are willing to become a lower level sponsor. (Men's and Women's Team, Small School).

[Support for Adding] That [donor support] was a factor, and that was up there with the fiscal feasibility ... It was feasible for us to add it, but it was more feasible because we had the support of some big boosters in the area (Men's Individual, Large School).

\section{Justification}

Our findings suggest that it was not always a person or a group who initiated the process of adding a sport. Rather, it was a mandated requirement by the NCAA which fell into three categories: (1) NCAA membership requirements, (2) conference membership requirements, or (3) gender equity compliance. Quotes below provide examples for these findings:

[Conference Membership Requirement] We are actually transitioning all of our sports from Division II to Division I. Whenever we started looking at doing that, the first thing you have to do is find a conference. That's your first step: Find a conference who will take you. The [XYZ] conference was interested, but they identify six sports of interest that they required all of their membership to have (Interview \#14, Men's and Women's Lacrosse, Medium School).

[Compliance] No, sand volleyball was in a sense, a replacement for dropping a men's and women's sport (Interview \#7, Sand Volleyball, Small School).

[NCAA Membership Requirement] We had been in the NCAA before, and the president that came into the university in 2006, wanted to move back to the NCAA" (Men's Team, Small School).

\section{Discussion of the Justification Phase Associated with the Organizational Determinant}

The organizational determinant is based on gaining public support and aligning with existing values. The previous quotes demonstrate that each sport provided a utility and was addressing a gap in the institution whether it be a gender equity initiative, compliance, or a conference requirement. In addition, this determinant speaks to athletics and in this case an individual sport being part of the university's marketing initiative rather producing separate efforts.

[Strategic Marketing] I think what part of the brilliance of this is in conjunction with the creation of football, the University has strategically initiated a national student recruitment program where the core of our students are going to come 
from ... [new regions]. Now, we have active recruiters in ... [in various regions throughout the country] and any time that our logo, that our brand, that our awareness can say, "Well, who is that?" and "Oh, they have physical therapy. They have chemical engineering. They are Carnegie Research Institution." The benefits: it's hard to put a number on it and point to it and say, "There I told you. But it is there." (Men's Team Sport, Large School).

\section{Evaluation}

While all institutions share some commonalities, each program will have a different culture or conditions related to their consideration of adopting a team for their program. Use of multiple lenses, such as athletic competitiveness, compliance, financial, community connection, and impact on individual and affiliated stakeholder groups, was evident during the evaluation phase. Actual evaluation occurred in the proposal of adding the sport: when narrowing down the sport options, when considering financial feasibility, and when obtaining institutional acceptance. This phase occurred mostly within the university, but on occasion evaluation occurred outside of the university, with the approval of stakeholders or external consultants, whose assistance and guidance is provided for an example below.

[Athletic Department] This is a working document that we've used, I would say for three years probably. I had an intern start it in the summer probably three years ago, maybe even longer. We just keep adding to it. We've gotten it down to about four sports now (Women's Individual: Large School).

It came from the university as a whole: the Trustees, the Admission, and the President's Office saying we think this can be strategic in helping us recruit in these areas, and we think it's something that we would like to do. "Athletics, what do you think?" How about doing the legwork and finding out the details, cost and that sort of thing (Interview \#1, Men's Football and Women's TBD: Small School).

[External Consultant] The thing I've always recognized is that there are people smarter than me out there. That's why I used this Title IX specialist to come in and do the evaluations because I think you got to make sure that what you're adding meets all the criteria, that it's not just an impulse deal. When you add a sport, it has value, and value across the board as a program, and what it does for your overall athletic program; and does it enhance it? And the investment you put into it; is there a return on it that's positive and it fits all the criteria? (Interview \#11, Women's Sand Volleyball and Women's Golf, Women's Individual, Large School).

\section{Discussion Associated with the Contextual and Project Determinants}

This determinant considers both internal and external stakeholders as well as impact. From the quote below the athletic administrator points to a number of stakeholders 
who were involved in the decision to add football at the school. Football has been known to provide students an opportunity to participate in a traditional college experience, while the community often feels a positive economic impact connected to the hospitality industry. The sentiment below considers a number of stakeholders but also points to the project determinant focused on the economic impact of a decision.

[Community Acceptance] . . . would say there are outside entities that were very involved: the City, the County, the Chamber of Commerce, alumni, [and] donors. The conference provided a very significant amount of data. Financial data and operational data were examined from other institutions that had created a football program in the last 10 to 15 years. There was a great deal of outside input but logistically, operationally, and financially, the plan was put together by a combination of athletic and university administration (Interview \#9, Men's Football, Large School).

These findings present an interesting note as the theoretical model suggests seeking out solutions or a de-escalation exit strategy (Hutchinson \& Bouchet, 2014b), while the emerging process recognizes that the sport being considered may be the only choice because it is a requirement, or because the sport was being considered due to its popularity. For example, adding (escalating) or not adding lacrosse (de-escalating exit strategy) would be the only option versus adding lacrosse or water polo (only escalating with no de-escalating exit strategy). Rather than a comparative analysis between multiple sports, a feasibility analysis took place to determine if the sport was a good fit athletically, academically, and socially; and would the benefits outweigh the costs for that institution?

\section{Acceptance}

Whether or not the sport being added was a part of a requirement or a request, a level of buy-in was part of the process. Most athletic directors mentioned a need to make sure that a majority of the departments, faculty, and staff was on-board prior to any public announcements being made about the sport. Community opinion also became a necessary part of the decision-making process.

[Faculty] It didn't slow the decision-makers' thinking down by any means. There were certainly questions among faculty about spending this money. Our President was very open and very public about his enthusiasm about it. Faculty questioned whether we should be spending that much money (Interview \#10, Men's and Women's'Lacrosse, Small School).

[Institutional Administration] . . . We did a pretty comprehensive presentation and the President was supportive of that (Interview \#6, Women's Soccer, Large School). 
[Low Resistance] It's something our athletic director and president saw [as] potential [as well as] the board of trustees. They brought admissions on board as an opportunity to increase enrollment, and the university made a commitment to do it. I don't think there was any pressure from anybody, because I think truthfully, we were naive to the sport (Interview \#7, Sand Volleyball, Small School).

\section{Discussion Associated with the Psychological Determinant}

In regards to Escalation of Commitment, this determinant was concerned with processing of decisions in such a way that facts might be manipulated to reach justification for the desired decision. Over the past few decades there has been a call for more accountability and transparency within athletics. Not in every case, but from the findings most athletic administrators discussed that a feedback loop, accountability, and expectation of buy were expected before a sport could be adopted at their institution.

\section{Authorization}

Through the interview process, several directors highlighted who was involved in the approval and authorization of adding a sport. Findings here are summarized and supported by quotes from the participations.

[Board of Trustees and Subcommittees] I think it unfolded at its own pace. There wasn't a deadline out there, but at the same time, I mean, it had a schedule of advancing. A, B and $\mathrm{C}$ needed to be accomplished to get it in a formal proposal, to be examined by subcommittees, so the board of trustees would then forward a recommendation to all the boards (Interview \#9, Football, Large School).

[President, Faculty and Board of Trustees] He was very forward-thinking and there was a segment of the faculty that was anti, but he had general support among the faculty. He had great support among the Board (Interview \#10, Men's and Women's Lacrosse, Medium School).

[President] We just took this to the President and she approved it; and she agreed. Not approved, but she agreed to that. We told her what we were doing, and she agreed with it. We don't want any committees on the campus or anything (Interview \#8, Women's Sand Volleyball, Small School).

\section{Approach and Leadership}

To answer RQ2 (what might the new decision-making model look like when adding a team to a university's athletic department?), we summarized our findings and organized the new themes into a model in Figure 1: Proposed Decision-making Process to Add a Sport to NCAA Division I Institutions. The new model demonstrates the general path(s) the decision to add a sport takes at an institution based on our data. Depending on the driving force or originator of the idea to add the sport, the pro- 


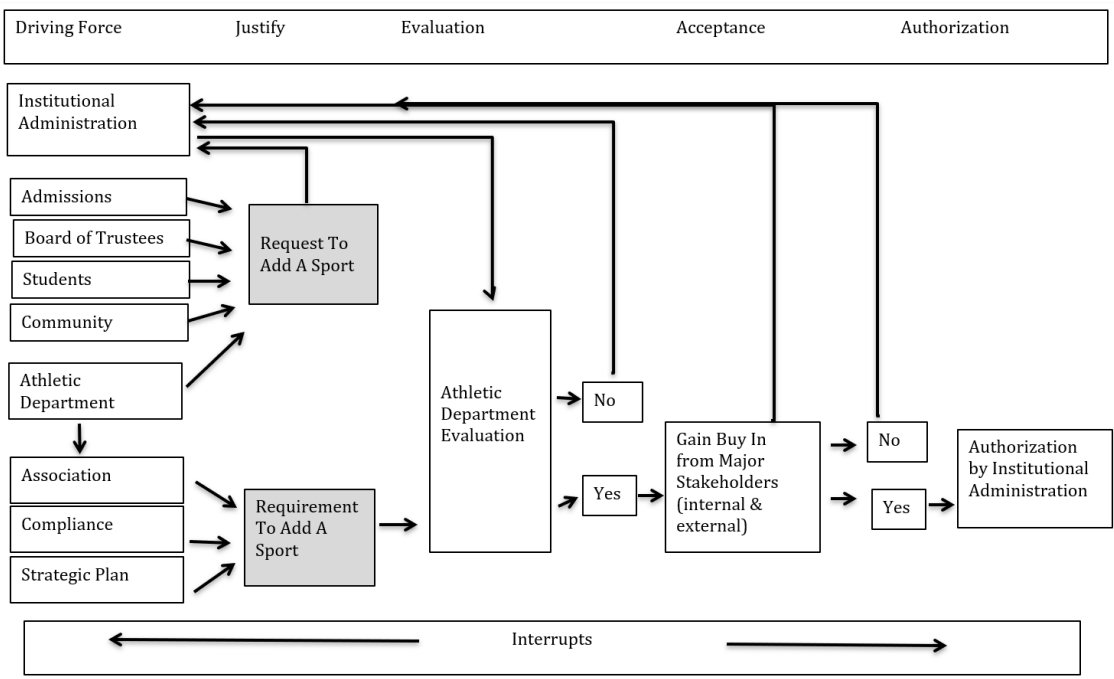

Figure 1. Proposed decision-making process to add a sport to NCAA Division I institutions.

cess might look slightly different. However, the findings illustrate common themes or phases of driving forces, justification, evaluation, acceptance, and authorization. While Table 3 describes the themes from our data, Figure 1 illustrates the themes in our new model, as they relate to the phases of Mintzberg et al.'s (1976) work. The themes are considered alongside of the elements of the theoretical framework used as a heuristic in this study, along with that of Mintzberg et al.'s (1976) Structure of "Unstructured" Decision Processes.

Our findings that present the process and emerging approach to add a sport are consistent with Mintzberg's (1976) Structure of "Unstructured" Decision Processes. However, the emerging process lends itself to a more transformational guide. The theoretical framework starts with identifying and clarifying a problem. However, the emerging approach can be more proactive in nature, enhancing or providing a new experience, or considering new opportunities.

The proposed decision-making process to add a sport to NCAA Division I institutions model illustrates the various phases of decision-making detailed with our emergent themes and data. We incorporated the first phase of the driving force of where the push to add a sport originated from, (such as: students, board of trustees, compliance, and the athletic department itself, among others), and linked this phase to phase 2 , justification.

Justification helps to reaffirm the driving force, and poses as the first gatekeeper in the decision-making process. As we found, there are times when the justification stems from an NCAA mandate, which moved the process along quicker than when the justification was rooted from a different driving force. 
Next, phase 3 involves the athletic department performing a robust evaluation of fit between the potential new sport and the institution. As our data suggest, this phase was primarily conducted internally within the athletic department and focused on financial feasibility while determining whether or not external acceptance of the additional sport would be positive or negative.

Acceptance is the next phase of our model, or to parallel Mintzberg et al. (1976), is positioned as the alternative interruption aspect. At the acceptance phase in our model, based on our data we found this to be the last critical barrier to adding a sport, and the last time that a potential de-escalation exit strategy could be implemented prior to the final phase of authorization. Acceptance involved gaining support from external stakeholders, after the internal evaluation phase was completed and successful in gaining final internal stakeholder support.

The last phase in our model is authorization, and occurs when all processes of the decision-making have been passed. Once this phase has been achieved, our data saw internal and external stakeholders give their final support and approval for the addition of the sport. We next discuss various implications of our findings while detailing limitations and future research.

\section{General Discussion}

As evidenced from our current findings, entrapment and escalation of commitment remain in the collegiate athletic decision-making processes (Brockner et al., 1986; Hutchinson \& Bouchet, 2014b). However, our findings demonstrate an emerging decision-making process and model that emphasizes the acceptance phase and advances the understanding of the various determinants of escalation of commitment to add an intercollegiate sport. We, therefore, have advanced sport managers' and researchers' understanding of the escalation of commitment among the decision-making process of adding an intercollegiate sport. Additionally, in several instances, athletic directors cited, and advised, the need for gaining "buy in" from every level of the administration and key stakeholder groups (i.e., social determinants and contextual determinants) before formally adding the sport in question. This illustrates a built-in exit strategy of de-escalation if buy-in from every level of administration and stakeholders was not achieved from the beginning. The inclusion of everyone's support and buy-in with a complete understanding of the commitment warranted by the decision at hand helped leaders avoid escalating their commitment to the decision to add a sport later. Such inclusion of everyone's support to help avoid later escalation highlights Hutchinson and Bouchet's (2014b) notion to include exit strategies of de-escalation early in the decision-making process. Our findings corroborate this notion and we depict strategies with feedback arrows in the Proposed Decision-making Process to Add a Sport model (Figure 1). The general sentiments are provided from one of participant's interviews:

First of all, we had to get buy-in from the President. We did a pretty comprehensive presentation and the President was supportive of that. Then we 
took it before our faculty athletic committee that is made up of faculty members from every college and they were supportive. Then we (presented to) the Women and Gender Advocacy Committee on campus, and then the University Budget Committee. We had all those conversations internally (Interview \#6, Women's Soccer, Large School).

\section{Theoretical Implications}

Our study advances and adopts the Mintzberg et al. (1976) unstructured decision-making model for NCAA institution decision makers looking to add a sport. While we used the Mintzberg et al. (1976) phases as a foundation for our study, our data and adapted phases advance Mintzberg and colleagues work (1976). Doing so allows us to enhance the understanding of structured unstructured decision-making processes in the intercollegiate sport context.

Further, we also add to the understanding of the escalation of commitment and de-escalation of commitment work in sport by illustrating evidence that when leaders in athletic departments adhere to our model, they can potentially avoid the negative issues related to the escalation of commitment. Thus, our model inherently helps to highlight the importance of potential de-escalation exits throughout the decision-making process at each phase in the model. Namely, the acceptance interruption phase provides a pathway towards rejecting a potentially dangerous financial decision for athletic departments and universities.

Additionally, our model helped to modernize the longstanding escalation of commitment and entrapment (Brockner et al., 1986) that has been evident among intercollegiate sport decision-makers (Hutchinson \& Bouchet, 2014b) by integrating each of the escalation of commitment determinants into one theoretical model. We found that the social determinant was responsible as a key driving force in our model, as noted earlier that community stakeholders not only proposed, but helped to support sport adoption initiatives. Next, we note how the organizational determinant was a key part of the justification aspect in our model. Specifically, our data show an emphasis on how this determinant aided the decision-makers' ability to gain buy-in from the community, specifically when there was a request to add a sport (Figure 1). Related to the organizational determinant's role in gaining buy-in from the community are the contextual and project determinants, which further emphasize the need to involve both internal and external stakeholders during the driving force and justification parts of our model while determining the exact impact the addition of a sport can have on the campus community. Our data specifically mention the addition of football to a university, and within our model's parts of driving force and justification, the agreement between internal stakeholders (i.e., athletic director and university officials) and external stakeholders (i.e., the surrounding community) was bolstered as the external stakeholders realized the potential positive economic gain the addition of football could result in for local businesses and individuals. Therefore, when the contextual and project determinants are working in sync with various driving forces, the justification aspect of our model is more easily reached and even further evident once decision-makers gain the acceptance portion of our 
model. The final determinant - the psychological - dealt with how facts can at times be manipulated to make arriving at a desired decision easier and falsely justified. Our data illustrate, as does our model, how important feedback loops are throughout the entire decision-making process for adding a sport. Throughout each aspect of our model are arrows highlighting feedback avenues back to institutional administration, emphasizing keeping those higher-up leaders in the know as well as to guard against such manipulation of facts. Therefore, our model has integrated each of the five escalation of commitment determinants into Mintzberg et al.'s (1976) model to synthesize two important concepts related to adding an intercollegiate sport. We next detail the practical implications of our findings and model.

\section{Practical Implications}

Our findings and model can help athletic administrators currently, as many deliberate the potential to add or remove various sport teams against the backdrop of a potential COVID-19 related economic down turn. Already, the COVID-19 pandemic has negatively and significantly impacted the U.S. economy, including the financial outlook for universities (Weaver, 2020). The current unknown state of university athletic funding recently led decision-makers at the University of Cincinnati to eliminate their men's soccer team (Russo, 2020).

Current leaders in athletic departments can use our model to help guide their decision-making during COVID-19 in regards to adding or removing sports at their NCAA institutions. By adhering to our phases, we believe that athletic directors and administrators can potentially avoid an escalation of commitment scenario after the COVID-19 pandemic by ensuring all of our model's phases have been thoroughly vetted and approved. The inclusion of gaining buy-in from all levels in our acceptance interruption phase points to the importance of gathering the proper amount of internal and external stakeholder approval. During the potential economic downturn related to the 2020 pandemic, the feasibility studies performed during the evaluation phase also become more important with speculation of future sport seasons without fans and ticket revenues unknown.

\section{Limitations and Future Research}

We would be remiss not to mention certain limitations to our study. The first limitation is inherent to most qualitative research, particularly interview research with a relatively small sample size, and that is the lack of generalizability. Despite our sample size of 15 individuals representing a wide-variety of institutions and six conferences, we cannot say for certain that our findings would generalize to a wider population of similar participants across more institutions. Therefore, there may be differences in the decision-making process at the Division II and Division III NCAA levels. Our next limitation is that we do not have data prior to the 2008 recession on the decision-making processes within athletic departments with the same theoretical framework that we used. Therefore, we cannot say how the 2008 recession may have affected our model or how the model may have looked prior to 2008 . While the limitations are noted, we do believe that future research can help address the limitations 
in the following ways. First, a more robust data collection can be undertaken to capture more participants from institutions that were not captured in our current sample. Researchers would do well to use a social network approach to help aid a snowball sampling technique to gain more participants, and potentially be able to generalize findings to a wider audience. Second, while going back in time to interview intercollegiate athletic decision-makers before the 2008 recession is not possible, researchers can replicate our study under the current COVID-19 pandemic conditions. The pandemic conditions are economically similar (though not yet a recession at the time of this writing) to the 2008 recession (Weaver, 2020). We believe it would be interesting and valuable to further assess our model to interview current college athletic decision-makers as they go through the decision-making process to add or remove sport teams due to the pandemic. Several institutions have already gone through the process as evidenced by University of Cincinnati removing men's soccer, Old Dominion cutting wrestling, and conversely, Plymouth State adding men's swimming and Indiana Tech adding women's ice hockey (Russo, 2020).

\section{Conclusion}

COVID19 has changed the face of sports like no other time in history. Most sporting institutions are in the midst of reorganizing, restructuring, and in the coming years rebuilding. While there is a mass elimination of college sports, there are a number of institutions adopting new sports. Factors post COVID such as the economy emerging from a recession, and new collegiate realignments, will highlight the need for colleges to add sports. This is in addition to needs such as for enrollment, good publicity, and to return campuses to traditional normal social activities that students have come to know and expect from college life. Our model offers guidance for those intercollegiate athletic leaders who engage in the decision-making process of adding a sport in the coming years as institutions emerge from the COVID 19 pandemic and assess growth strategies in the future.

Overall, our study provides a deeper understanding to the decision-making processes related to adding an intercollegiate sport through a framework of unstructured structured decision-making and the escalation of commitment phenomenon. We found that when certain structures are evident, that college athletic decision-makers engaged in phases of driving force, justification, evaluation, acceptance, and authorization throughout the process. We form the phases into an adapted model of Mintzberg et al.'s (1976) work as a way to help practitioners through future decision-making processes of adding a sport as well as guiding future researchers by inviting further examination of our model. 


\section{References}

Allen, M. (1999, March 31). UConn finds Rich Off-court gains in Basketball Power. Retrieved July 1, 2020, from https://www.nytimes.com/1999/03/31/nyregion/uconn-finds-rich-off-court-gains-in-basketball-power.html

Armstrong, K. (2009, December 3). Hofstra Eliminates 72-Year-Old Program. The New York Times. Retrieved from http://www.nytimes.com/2009/12/04/ sports/ncaafootball/04hofstra.html?_r=0.

Axson, S. (2014, August 19). Hawaii AD: 'Possibility' school may drop football. Sports Illustrated Online. Retrieved from: http://www.si.com/collegefootball/2014/08/19/hawaii-football-program-budget-deficit.

Batley, J. W. (2011). Athletic academic reform: Does the level of spending on academic services by athletic departments affect the academic progress rates of revenue sports? (Doctoral dissertation). Retrieved from MPA/MPP Capstone Projects. (90)

Benford, R. D. (2007), The college sports reform movement: Reframing the edutainment industry. The Sociological Quarterly, 48, 1-28.

Bouchet, A., \& Hutchinson, M. (2010). Organizational escalation to an uncertain course of action: A case study of institutional branding at Southern Methodist University. Journal of Issues in Intercollegiate Athletics, 3, 272-295. Bouchet, A., \& Hutchinson, M. (2011). Organizational escalation and retreat in university athletics: Brand insulation in Birmingham-Southern College's transition to Division III athletics. Journal of Intercollegiate Sport, 4, 261-282.

Bowen, W. G., \& Levin, S. A. (2003). Reclaiming the game: College sports and educational values. Princeton, NJ: Princeton University Press.

Brockner, J., Houser, R., Birnbaum, G., Lloyd, K., Deitcher, J., Nathanson, S., \& Rubin, J. Z. (1986). Escalation of commitment to an ineffective course of action: The effect of feedback having negative implications for self-identity. Administrative Science Quarterly, 31(1), 109-126.

Brockner, J., \& Rubin, J. Z. (1985). The social psychology of conflict escalation and entrapment. New York, NY: Springer-Verlag

Brockner, J., Shaw, M. C., \& Rubin, J. Z. (1979). Factors affecting withdrawal from an escalating conflict: Quitting before it's too late. Journal of Experimental Social Psychology, 15(5), 492-503.

Brooker, G., \& Klastorin, T. D. (1981) To the victors go the spoils? College athletics and alumni giving. Social Science Quarterly, 62, 744-50.

Burton, L., \& Peachey, J. W. (2014). Ethical Leadership in Intercollegiate Sport. Journal of Intercollegiate Sport, 7(1), 1-10.

Clotfelter, C. (2003). Alumni giving to elite private colleges and universities. Economics of Education Review, 22(3), 109-120.

Creswell, J.W. (2009). Research design: Qualitative, quantitative, and mixed methods approaches (3rd ed.). Los Angeles, CA: Sage. 
Getz, M. \& Siegried, J. (2010). What does intercollegiate athletics do to for colleges and universities? Retrieved from http://vanderbilt.edu/econ/wparchive/workpaper/vu10-w05.pdf

Goodman, P.S., Bazerman, M.H., \& Conlon, E.J. (1980). Institutionalization processes in organizational change. In B.M. Staw \& L.L. Cummings (Eds.), Research in organizational behavior (Vol. 2). Greenwich, CT: JAI Press.

Hutchinson, M., \& Berg, B. K. (2015). Institutions of higher commitment: A case study of de-escalation and American football's decisive role in intercollegiate athletics. Sport Management Review, 18(3), 464-480.

Hutchinson, M., \& Bouchet, A. (2014a). Achieving organizational de-escalation: Exit strategy implementation among United States collegiate athletic departments. Sport Management Review, 17(3), 347-361.

Hutchinson, M., \& Bouchet, A. (2014b). Organizational redirection in highly bureaucratic environments: De-escalation of commitment among Division I athletic departments. Journal of Sport Management, 28(2), 143-161.

Jones, W. A. (2014). Does discontinuing intercollegiate football correlate with institutional attractiveness to potential students? Evidence from three universities. Journal of Issues in Intercollegiate Athletics, 7, 92-113.

Keil, M., \& Robey, D. (1999). Turning around troubled soft-ware projects: An exploratory study of the de-escalation of commitment to failing courses of action. Journal of Management Information Systems, 15(4), 63-87.

Lawrence, J., Ott, M., \& Hendricks, L. (2009). Athletics reform and faculty perceptions. New Directions for Higher Education, (148), 73-81.

Mahony, D. F., \& DeSchriver, T. D. (2008). The big business of college sports in America. In B. Humphreys \& D. Howard (Eds.), The business of college sports (pp. 225-252). Westport, CT: Praeger. McCormick, R. \& Tinsley, M. (1987). Athletics vs. academics? Evidence from SAT scores. The Journal of Political Economy, 95(5), 1103-1116.

Milstein, S., \& Dixon, M.A. (2019). Exploring the buyer-seller mismatch in amateur sport adoption process. International Journal of Sport Management, 20, 297327.

Mintzberg, H., Raisinghani, D., \& Theoret, A. (1976). The structure of "unstructured" decision processes. Administrative Science Quarterly, 21, 246-275.

Monks, J. (2003). Patterns of giving to one's alma mater among young graduates from selective institutions. Economics of Education Review, 22, 121-130.

Patton, M. Q. (1990). Qualitative evaluation and research methods (2nd ed.). Newbury Park, CA: Sage.

Richards, L. (2005). Handling qualitative data. London, England: Sage.

Ross, J., \& Staw, B. M. (1993). Organizational escalation and exit: Lessons from the Shoreham Nuclear Power Plant. Academy of Management Journal, 36, 701-732.

Roy, D., Graeff, T., \& Harmon, S. (2008). Repositioning a university through NCAA Division I- A football membership. Journal of Sport Management, 22, 11-29. 
Russo, R. D. (2020, April 20). If colleges cut sports programs, could new models emerge? Retrieved from https://www.detroitnews.com/story/sports/college/2020/04/20/colleges-cutting-sports-teams-new-modelsemerge/111574820/

Saldaña, J. (2016). The coding manual for qualitative researchers. Thousand Oaks, CA: Sage.

Sandy, R. Sloane, P. (2004). Why do U.S. colleges have sports programs? In John Fizel and Rodney Fort (Eds.), Economics of College Sports (pp. 87-109). Westport, CT: Praeger.

Siritarungsri, B., Grant, J., \& Francis, K. (2013) Five success factors in elite interviewing for qualitative research. Journalism and Mass Communication, 3 , 69-75.

Staw, B.M. (1981). The escalation of commitment to a course of action. Academy of Management Review, 6, 577-587.

van Holm, E., \& Zook, S. (2016). Returns for a touchdown? Universities entering college football. Retrieved from the Social Science Research Network website: http://dx.doi.org/10.2139/ssrn.2733761

Weaver, K. (2020, April 15). First they dropped wrestling, then soccer. What's next for NCAA mid-majors? Retrieved from https://www.forbes.com/sites/karenweaver/2020/04/15/first-wrestling-then-soccer-whats-next-for-ncaa-mid-majors/\#13bb32f62777

Wunnava, P. V., \& Lauze, M. A. (2001). Alumni giving at a small liberal arts college: Evidence from consistent and occasional donors. Economics of Education Review, 20(6), 533-543. 